\title{
Relationships between students' and instructional variables with satisfaction and learning from a Web-based course
}

\author{
Kian-Sam Hong*,1 \\ Faculty of Cognitive Sciences and Human Development, Universiti Malaysia Sarawak, \\ 94300 Kota Samarahan, Sarawak, Malaysia
}

Received 28 March 2002; accepted 15 May 2002

\begin{abstract}
The author discusses the results of a study about the effect of students' and instructional variables on satisfaction and achievement in a Web-based course. Results indicated that gender, age, learning styles, time spent on the course, and perceptions of student-student interactions, course activities, and asynchronous Web-based conferences were not related to satisfaction and learning outcomes. Those students who entered the course with better Cumulative Grade Point Average (CGPA) scores achieved higher final grades in the course, but did not express more satisfaction with the learning environment. Computer experience did not influence achievement but experienced computer users were more satisfied with the course. Students who perceived the student-instructor interactions positively felt that their discussion group had performed well during the conferences, and viewed the learning materials used in the conferences positively improved grades and were more satisfied with the course. Students expected instructor-led learning. There is a need to explicitly design an organising strategy to assist students in completing the problem-based learning processes during the Web-based conferences.

(C) 2002 Elsevier Science Inc. All rights reserved.
\end{abstract}

Keywords: Web-based course; Student-instructor interactions; Satisfaction; Achievement

* School of Education, University of Otago, Dunedin, New Zealand.

E-mail addresses: hks@paradise.net.nz, hon00125@student.otago.ac.nz (K.-S. Hong).

${ }^{1}$ Valid until August 31, 2002; after August 31. use hksam@fcs.unimas.my and Universiti Malaysia Sarawak’s address above. 